\title{
Executive Function Deficits Mediate Poverty's Effects on Academic Achievement: Target for Intervention in At-Risk Children
}

\author{
Bruce E. Wexler ${ }^{1}$, Ahmet Esat Imal' ${ }^{2}$, Brian Pittman ${ }^{3}$, Morris D. Bell ${ }^{3}$ \\ ${ }^{1}$ Department of Psychiatry and the Connecticut Mental Health Center, Yale University, New Haven, CT, USA \\ ${ }^{2}$ Department of Psychiatry, Yale University, New Haven, CT, USA \\ ${ }^{3}$ Department of Psychiatry and the West Haven VA Medical Center, Yale University, New Haven, CT, USA \\ Email: *bruce.wexler@yale.edu
}

How to cite this paper: Wexler, B. E., Imal, A. E., Pittman, B., \& Bell, M. D. (2020). Executive Function Deficits Mediate Poverty's Effects on Academic Achievement: Target for Intervention in At-Risk Children. Creative Education, 11, 406-419.

https://doi.org/10.4236/ce.2020.113029

Received: February 17, 2020

Accepted: March 23, 2020

Published: March 26, 2020

Copyright (c) 2020 by author(s) and Scientific Research Publishing Inc. This work is licensed under the Creative Commons Attribution International License (CC BY 4.0).

http://creativecommons.org/licenses/by/4.0/

\begin{abstract}
Aim: Determine whether effects of poverty on academic achievement are mediated by effects of poverty on executive cognitive functions. Methods: Web-based classroom-administered tests assessed executive function in 5717 children grades k-8 in 40 schools, and poverty level and academic achievement for each school were drawn from US Department of Education data. Boot-strapping procedures were used to evaluate mediation by executive function of the association between poverty and academic proficiency. Results: Executive function and academic achievement were both related to school poverty (pearson $\mathrm{r}-0.50$ to $-0.65, p=0.0009$ to $<0.0001$ ). Estimated indirect effects of poverty on reading $(-0.26,95 \% \mathrm{CI}:-0.47,-0.07)$ and math $(-0.23,95 \%$ CI: $-0.44,-0.06)$ through effects on executive function were significant. Controlling for executive function, effects of poverty on reading $(-0.58$ to -0.31$)$ and math $(-0.59$ to -0.35$)$ were diminished, indicating partial mediation of effects of poverty on reading and math via effects on executive function. Conclusion: Interventions that enhance executive function in children in impoverished and/or violent environments could mitigate damaging effects of these environments on neurocognitive and associated life and health outcomes. Without intervention, many young adults in troubled areas of the world will be ill-prepared for productive function in society.
\end{abstract}

Key Notes: Analysis in 5717 children shows that poverty compromises academic proficiency in large part by compromising executive cognitive skills necessary for learning, health and work. World-wide nearly 400 million children live in impoverished circumstances that often include high levels of violence and domestic instability. Without interventions to improve executive functions, a large number of young adults are likely to have health problems and be ill-prepared for productive function in their communities. 


\section{Keywords}

Academic Achievement, Executive Function, Poverty, Violence, Neurocognitive Development

\section{Introduction}

Executive cognitive functions (EF), including attention, self-control and memory, powerfully predict a wide range of important life outcomes starting with academic success in elementary school and beyond, absence of legal problems, and multiple health outcomes. Children with stronger EF engage more effectively with classroom learning activities (Nelson et al., 2017) and have higher reading and math achievement in elementary school (Yeniad et al., 2013; Best et al., 2011; Cantin et al., 2016). A 16-year longitudinal study of $12,0003^{\text {rd }}$ grade children found that the $17 \%$ with the lowest attention skills had a $7.6 \mathrm{X}$ greater chance of becoming high school drop outs with the accompanying life consequences (Pingault et al., 2011). In a study following 1000 children from birth to age 32, childhood self-control predicted metabolic syndrome, respiratory disease, periodontal disease, inflammation, sexually transmitted infections, tobacco and other substance dependence, personal finances and criminal offences, controlling for effects of general intelligence and social class (Moffitt et al., 2011).

Other research has established that children raised in impoverished communities (Noble et al., 2007; Welsh et al., 2010; Blair et al., 2011; Haft \& Hoeft, 2017; Ready \& Reid, 2019) and in communities with high levels of violence have lower EF (Heissel et al., 2018). Compromised development of brain systems associated with EF in children from these disadvantaged backgrounds has been demonstrated as early as 9 months of age (Tomalski et al., 2013) and is evident in measures of brain structure as well as function (Noble et al., 2015). Research has identified multiple mechanisms through which disadvantaged and problematic childhood rearing environments compromise development of EF, and associated brain structures with life-long consequences (Jensen et al., 2017). These mechanisms include parental stress, fatigue and anger (Luby et al., 2013), less time spent by parents talking to and reading to their children (Hammond et al., 2012), fewer resources for instructional toys and exposure to interesting places and activities, exposure to environmental toxins, poor nutrition and sleep, and exposure to violence and stress (Sharkey et al., 2012). A recent study found that children in a city in the United States slept significantly less the night after a violent crime in their neighborhood, and had elevated cortisol levels the next morning (Heissel et al., 2018). Controlled studies in animals and correlational studies in children demonstrate a link between elevated cortisol and compromised development of EF (Blair \& Raver, 2016).

These two sets of findings together strongly suggest that compromised EF is an important mechanism for the impact of poverty and violence on academic 
achievement, health and other important life outcomes. This has led to suggestions that because of the great individual and social costs associated with growing up in poverty and associated low EF, interventions are urgently needed to improve EF in children at risk for compromised EF development (Moffitt et al., 2011; Luby et al., 2013; Diamond \& Ling, 2016). However, direct evidence demonstrating if and to what extent $\mathrm{EF}$ dysfunction mediates the impact of poverty on academic and life outcomes is, in fact, sparse. In a study of $915^{\text {th }}$ grade children in poverty community schools, Waber et al. (2006) found that EF accounted for about $40 \%$ of the variance in math and reading proficiency test scores. Although this study found that variance in EF among children in poverty area schools contributes significantly to academic outcomes, the same was found among children living in affluent communities. The study was not designed to examine whether differences between children in high poverty vs. affluent communities in academic outcomes were mediated by differences in EF. In a more direct assessment of mediation in a study of 49 children (54 - 66 months old) in a small town, Dilworth-Bart et al. (2012) found that EF did significantly mediate the effects of socioeconomic status (SES) on math competency, but notes that the study was limited both by sample size and constricted range of SES, as the children were mostly from well-educated middle-income homes. The most compelling existing data of mediation by EF deficits of the effects of poverty on academic outcomes is provided by a study of the development of brain regions important in EF (Hair et al. 2015). In this longitudinal brain imaging study of 389 children including $25 \%$ from households with reported income less than $200 \%$ of federal poverty levels, $10 \%-15 \%$ of the effects of poverty on academic outcomes were accounted for by the measured effects of poverty on brain development.

The present study of a large sample of children from kindergarten to $8^{\text {th }}$ grade in schools located in a wide range of socioeconomic settings in the United States aimed to provide a more definitive test of the hypothesis that EF abilities mediate the relation between compromised rearing environments and academic achievement, and provide additional estimates of the magnitude of the mediation effect. Such data, together with existing data, would provide compelling evidence for allocating funds to develop and implement existing interventions to promote EF development in communities compromised by poverty and disrupted by violence (LCAH, 2019).

\section{Methods}

\subsection{Participants}

Participants were all children $(\mathrm{n}=5717)$ grades K-8 in schools $(\mathrm{n}=40)$ across the United States in which at least 20 children in a single grade used a cognitive skills training program purchased by their school from C8 Sciences and had valid on-line classroom-administered tests of EF. Individual EF data were aggregated at the school level since available socioeconomic and academic proficiency 
data were available only at the school level. In order to have a large enough sample to create a representative value for each school, schools were only included if there were at least 20 children in a single grade with valid assessments on all three EF tests. Since school officials selected the program for use in their curriculum and all data analysis was on the group level without identifying information on individual children, the Yale Human Investigations Committee determined that individual consent was not needed and all procedures were in accordance with the Helsinki Declaration of 1975, revised in 1983.

\subsection{School Socioeconomic Status and Academic Outcome}

The percentage of children eligible for free or reduced lunch based on family income was used as the indicator of the SES of the community of each school. Academic achievement was measured by the percentage of children meeting math and reading proficiency levels on school-administered state proficiency exams. All data were drawn from the US Department of Education, National Center for Education Studies (data available at https://www.niche.com).

\subsection{Measures of Executive Function}

EF outcomes were assessed with three web-based measures embedded in the cognitive skills training program and automatically presented, administered and scored in the classroom. EF measurements started on the third day of the program to give teachers and students time to be familiar with the program, and were given either one per day for three days or two per day for two days. Two tests (Flanker and Working Memory) followed precisely the design of tests in the $\mathrm{NIH}$ Toolbox of tests of EF (nihtoolbox.org). The third test is a Go/No-Go test of response inhibition, very similar to continuous performance tasks commonly used in research studies. The fact that the tests are done in the classroom environment adds ecological validity to the scores. But since the testing environment is not controlled and there are no direct observations of children while testing, test validity criteria are applied as part of the auto-scoring of all tests (see below).

The Flanker Test of focused attention uses reaction time on correct incongruent trials as its primary performance measure. In this task, children indicate by keyboard response the pointing direction (right or left) of the center arrow in a linear horizontal array of five arrows. On incongruent trials, the four "flanking" arrows point in the opposite direction of the central arrow. Following the procedure of the NIHToolbox, there are 29 congruent trials and 17 incongruent trials. Response times longer than $4500 \mathrm{msec}$ on incongruent trials and 3500 msec on congruent trials were so slow as to suggest classroom distraction or momentary disengagement from the test, and those trials were excluded. Response times faster than $150 \mathrm{msec}$ suggested random responding and such trials were also excluded. Tests with more than 4 incongruent "too slow" trials, more than 7 congruent "too slow" trials, more than 4 "too fast" trials, less than $75 \%$ correct on the congruent trials or fewer than 8 correct incongruent trials were considered invalid because there were not enough valid trials to reliably evaluate 
performance and because they suggested repeated distraction or disengagement. Finally, tests were considered invalid if average reaction time was more than two standard deviations from the mean.

The List Sorting Working Memory Test presents the child with a series of animals or household objects. The child must select the objects just seen from among a grid of 16 objects, clicking them in order from smallest to largest rather than the order in which they were presented. The test starts with a list of $2 \mathrm{ob}-$ jects. If the child completes the list accurately, list length is increased by one. If the child errs, the same length list is repeated. Two failed attempts at the same list length ends the test. The score is the sum of correct list lengths. The test has two parts. In part one, trials of animals and household objects alternate. In part two, animals and household objects are presented in the same trial, and the child must reorder the animals first and then the household objects. As a validity check, if a child was unable to report back two items in correct order, we considered it possible that the child did not understand or engage with the test and their scores were considered invalid.

The Go/No-Go Test of Response Inhibition instructs the child to press the space bar whenever a "Go" stimulus is presented but not when a "No-Go" stimulus is presented. There are three blocks with different stimuli, 50 stimuli per block with $40 \mathrm{Go}$ and 10 No-Go trials, randomized in sets of 10 with 8 Go and 2 No-Go in each set. In the first block "P" is the Go stimulus and " $\mathrm{R}$ " is the No-Go stimulus. In the second block this is reversed. In the third block, pictures of furniture are the Go trials and pictures of foods like cake and ice cream are the No-Go stimuli. Stimuli are presented for $400 \mathrm{msec}$ with a $1400 \mathrm{msec}$ response window after stimulus offset. Errors are indicated by display of a large red "X." Trials with response times greater than $2000 \mathrm{msec}$ were eliminated since the response was after presentation of another stimulus. Trials with response times less than $150 \mathrm{msec}$. were also eliminated because response was too fast to confidently be related to the stimulus. Tests with less than $85 \%$ correct response to Go-Trials were considered invalid because the child failed to establish the consistent response bias required to measure response-inhibition. Also, not responding due to general inattention or poor accuracy artificially elevates the rate of No-Go trials correctly skipped. Tests with more than 10 "too slow" trials or more than 15 "too fast" trials were also considered invalid because of concern that the children were attending inconsistently or responding randomly.

\subsection{Statistical Analyses}

Relations among EF, school SES and school academic achievement were evaluated using average grade-based $\mathrm{z}$-scores for children within each school (Figure 1). All variables were coded such that higher scores indicate better performance. Potential associations between levels of lunch subsidization, EF (Flanker, GNG, WMT), and reading and math proficiency were assessed using correlation analysis. Mediation by EF of the association between lunch subsidization and academic proficiency was evaluated as outlined by Baron and Kenny (1986). The 


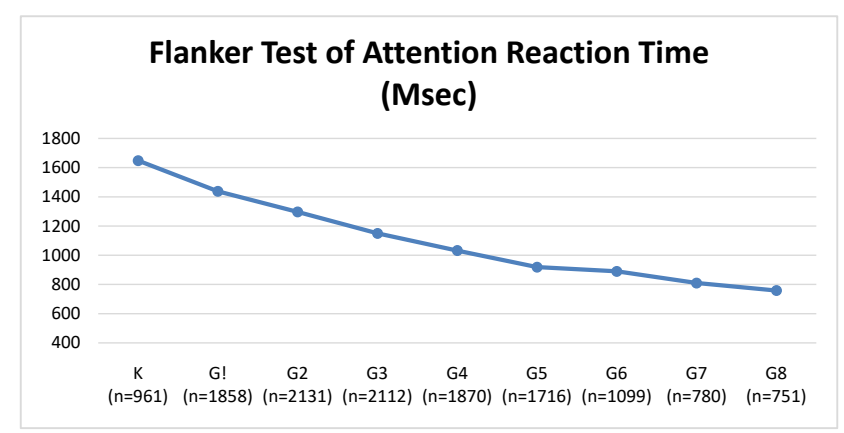

(a)

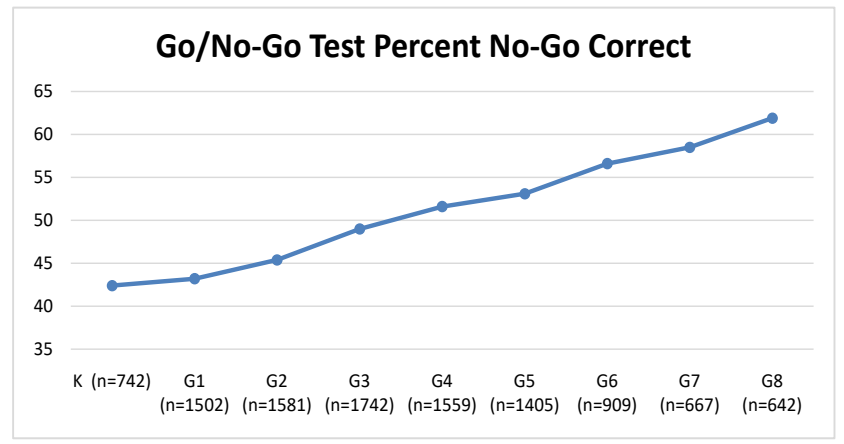

(b)

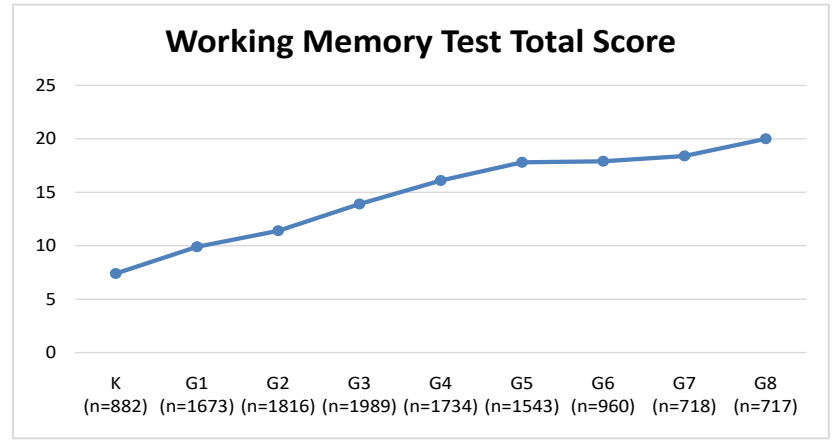

(c)

Figure 1. Age-related growth on three tests of Executive Function: Flanker Test of Focused Attention (reaction times on correct incongruent trials become faster); Go/No-Go Test of Response Inhibition (percent correct on No-Go trials); List Sorting Working Memory Test (total score).

estimated indirect effect was tested for significance using bootstrapping procedures (Preacher \& Hayes, 2004) with $n=5000$ samples. In lieu of testing the mediating effects of each EF measure separately, regression-based factor scores were estimated based on a one-factor solution for the Flanker, GNG, and WMT tasks. Despite its low factor loading, the GNG task was included in the calculation of the EF factor score so as to encompass all available information. Analyses were conducting using SAS, version 9.4 (Cary, NC).

\section{Results}

Growth of Executive Function: As expected, improvement in EF from $\mathrm{K}$ to $8^{\text {th }}$ grade is significant on all tests (effect of grade $p<0.0001$, Figure 1 ).

Relations Among EF, SES and Math and Reading Achievement (Table 1): Increased lunch subsidy was strongly associated with diminished performance on both the Flanker and WMT tasks and math and reading assessments. No associations with performance on the GNG task were observed.

Regression models (Table 2, Figure 2(a), Figure 2(b)) showed significant relations between lunch subsidization and $\mathrm{EF}(\mathrm{b}=-0.57, p<0.0001)$ and $\mathrm{EF}$ and both reading $(\mathrm{b}=0.46, p=0.002)$ and math $(\mathrm{b}=0.42, p=0.005)$ proficiency after controlling for lunch subsidization, supporting the mediation hypothesis. The estimated indirect effect was $(-0.57)(0.46)=-0.26$ on reading and $(-0.57)$ $(0.42)=-0.24$ on math, with both significant according to bootstrap results 
Table 1. Correlations among lunch subsidization, measures of executive function, and reading and math proficiency $(\mathrm{n}=40)$.

\begin{tabular}{cccccc}
\hline & Flanker & GNG & WMT & Read & Math \\
\hline Lunch & $\mathrm{r}=-0.50$ & -0.06 & -0.61 & -0.63 & -0.65 \\
& $p=0.0009$ & 0.72 & $<0.0001$ & $<0.0001$ & $<0.0001$ \\
Flanker & & -0.11 & 0.62 & 0.51 & 0.52 \\
& & 0.49 & $<0.0001$ & 0.0008 & 0.0006 \\
GNG & & 0.20 & 0.18 & 0.14 \\
& & 0.23 & 0.28 & 0.39 \\
WMT & & & 0.69 & 0.66 \\
& & & & $<0.0001$ & $<0.0001$ \\
Read & & & & & 0.95 \\
& & 0.126 & & & $<0.0001$ \\
Factor Loading & 0.883 & & & & \\
\hline
\end{tabular}

Lunch: \% students receiving free or reduced lunch; Flanker: (Flanker Test) reaction time to target (coded such that higher scores indicate better performance); GNG: (Go-No-Go task) correct percent; WMT: (Word Memory Test); Read: \% students reading proficient; Math: \% students math proficient.

Table 2. Summary of mediation analyses.

\begin{tabular}{|c|c|c|c|c|c|}
\hline Reading Proficiency & & & & & \\
\hline Model & Coefficient & Stderr & $\mathrm{T}(1)$ & $\mathbf{P}$ & R-square \\
\hline Read $=$ Lunch & -0.57 & 0.12 & -4.99 & $<0.0001$ & 0.40 \\
\hline $\mathrm{EF}=\mathrm{Lunch}$ & -0.57 & 0.12 & -4.83 & $<0.0001$ & 0.38 \\
\hline Read = EF (control lunch) & 0.46 & 0.14 & 3.26 & 0.002 & 0.53 \\
\hline Read = Lunch (control EF) & -0.31 & 0.13 & -2.39 & 0.02 & 0.53 \\
\hline \multicolumn{6}{|c|}{ Total effect $=-0.57 ;$ Direct effect $=-0.31 ;$ Indirect effect $=-0.26 ; \%$ mediation $=46 \%$} \\
\hline Bootstrap & Mean & Stderr & $\begin{array}{l}\text { Lower } \\
95 \% \text { CI }\end{array}$ & $\begin{array}{c}\text { Upper } \\
95 \% \text { CI }\end{array}$ & \\
\hline Effect & -0.26 & 0.10 & -0.47 & -0.07 & \\
\hline \multicolumn{6}{|l|}{ Math Proficiency } \\
\hline Model & Coefficient & Stderr & $\mathrm{T}(1)$ & $\mathbf{P}$ & R-square \\
\hline Math = Lunch & -0.59 & 0.11 & -5.27 & $<.0001$ & 0.42 \\
\hline $\mathrm{EF}=$ Lunch & -0.57 & 0.12 & -4.83 & $<.0001$ & 0.38 \\
\hline Math $=$ EF (control lunch) & 0.42 & 0.14 & 2.99 & 0.005 & 0.53 \\
\hline Math = Lunch (control EF) & -0.35 & 0.13 & -2.71 & 0.01 & 0.53 \\
\hline \multicolumn{6}{|c|}{ Total effect $=-0.59 ;$ Direct effect $=-0.35 ;$ Indirect effect $=-0.24 ; \%$ mediation $=40 \%$} \\
\hline Bootstrap & Mean & Stderr & $\begin{array}{l}\text { Lower } \\
95 \% \text { CI }\end{array}$ & $\begin{array}{c}\text { Upper } \\
95 \% \text { CI }\end{array}$ & \\
\hline Effect & -0.23 & 0.10 & -0.44 & -0.06 & \\
\hline
\end{tabular}




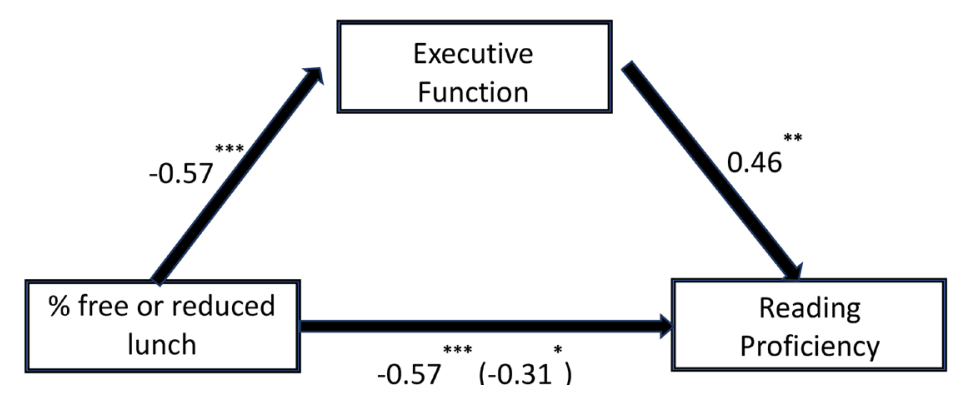

(a)

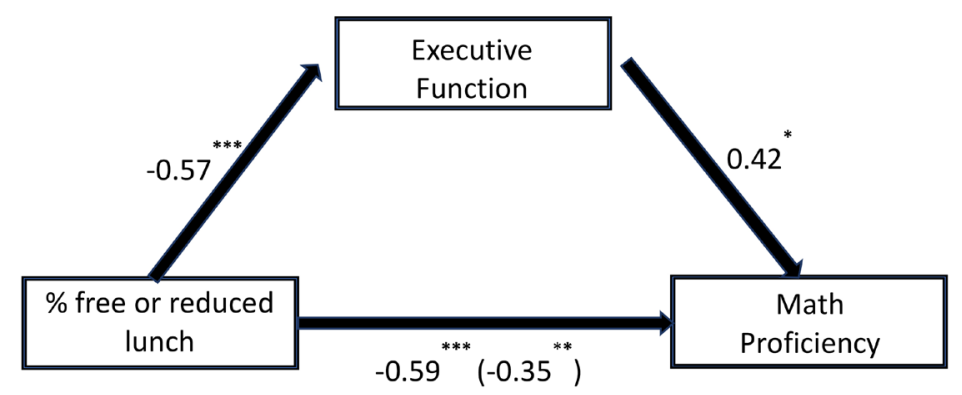

(b)

Figure 2. (a) Regression coefficients for relations between percent of children in the school receiving free or reduced lunch and Executive Function, Executive Function and Reading Proficiency, and percent of children in the school receiving free or reduced lunch and Reading Proficiency without and with mediation by effect of percent of children in the school receiving free or reduced lunch on Executive Function. ${ }^{\star *} p<0.001,{ }^{\star *} p<$ $0.01,{ }^{\star} p<0.05$. (b) Regression coefficients for relations between percent of children in the school receiving free or reduced lunch and Executive Function, Executive Function and Math Proficiency, and percent of children in the school receiving free or reduced lunch and Math Proficiency without and with mediation by effect of percent of children in the school receiving free or reduced lunch on Executive Function. ${ }^{* *} p<0.001,{ }^{* *} p<0.01,{ }^{*} p$ $<0.05$.

(reading: $-0.26,95 \%$ CI: $-0.47,-0.07$; math: -0.23 , 95\% CI: $-0.44,-0.06$ ). The effect of lunch subsidization, after controlling for EF, was significant, but diminished on both reading ( -0.58 to -0.31$)$ and math $(-0.59$ to -0.35$)$, consistent with partial mediation. $46 \%$ and $40 \%$ of the effect of lunch subsidization on reading and math proficiency was mediated via $\mathrm{EF}$.

\section{Discussion}

Previous research has established that EFs of focused attention, inhibition and working memory continue to develop throughout childhood, predict academic success, and are compromised in children from impoverished backgrounds. These findings have suggested that compromise in EF may be one important cause of lower academic achievement in children in poverty area schools. However, data confirming this hypothesis has been limited and some possibly even non-confirmatory e.g., The present study provides the first confirmation in a large and economically diverse sample that EF deficits substantially mediate the impact of poverty on academic achievement. These findings, together with the 
studies showing impact on brain development in regions associated with $\mathrm{EF}$, and mediation of the effects of poverty on academic achievement by alterations in brain development (Hair et al., 2015), support suggestions that childhood intervention to improve EF may have significant positive value at both individual and social levels.

"Poverty disproportionately affects the young. Worldwide, one in five children, a staggering 385 million, survive on less than US\$1.90/day (LCAH, 2019)." Of the children under the mandate of the UN Commission on refugees, nearly 3 million do not attend school

(https://www.unicef.org/eca/emergencies/latest-statistics-and-graphics-refugee-a nd-migrant-children). Over $40 \%$ of Syrian child refugees in surrounding countries are out of school, and millions more in Syria are exposed daily to the full range of environmental factors that compromise EF (Jensen et al., 2017). Similar conditions face additional millions of children in Yemen where thousands have died from starvation, 5 million are said to face starvation and 11 million are in need of humanitarian aid according to the United Nations, in a country of only 25 million

(https://www.savethechildren.net/article/yemen-further-one-million-children-ri sk-famine-food-and-fuel-prices-soar-across-country,

https://www.unicef.org/mena/press-releases/three-million-children-born-war-ye men). Without intervention, it is likely that large numbers of children will become young adults without the cognitive skills to function effectively in $21^{\text {st }}$ century societies, with increased medical disease ${ }^{8}$ and with the potential to burden and destabilize social organization rather than contribute to it.

These statistics portend serious risk for individual and societal well-being and stability. Current understanding of healthy brain development and the brain's neuroplastic potential provide evidence-based and targeted interventions to address this crisis (Diamond \& Ling, 2016; Jensen et al., 2017). Randomized controlled trials of in-home parenting interventions to support cognition-enhancing parent-child interactions for 9 - 24 month old children (Walker et al., 2005), and full-day child-care center providing games for $3-5$ year olds to improve EF found faster and greater cognitive development in the intervention groups with gains still evident when the children were 17 - 21 years old. Another 8-week RCT of a 2 times/week parenting skill and child EF training groups showed intervention-related enhancement of language function, social skills and ERP measures of attention-related brain function (Neville et al., 2013). A controlled study involving 759 children in 79 classrooms trained teachers to use special games and pedagogic techniques to enhance $\mathrm{EF}$ and found broad EF gains in children in low SES schools (Blair \& Raver, 2014). Studies in 500 to 1000 children of low-cost, easily scaled, web-based EF training games for classroom use found increases in EF (Kavanaugh et al., 2018) and far-transfer to improved performance on school-administered reading and math achievement tests (Wexler et al., 2016). As Luby wrote (Luby, 2015), "In developmental science 
and medicine, it is not often that aspects of a public health problem's etiology and solution become clearly elucidated. It is even less common that feasible and cost-effective solutions to such problems are discovered and within reach." Subsequent work, including that described in this report, provide additional support for these important but yet to be widely acted on assessments. There are neuroscience-informed, evidence-based interventions to address the urgent problems related to compromised neurocognitive development in children raised in poverty and/or exposed to violence. Application of these interventions in areas of poverty, violence and domestic instability could have positive public health outcomes on the same scale as vaccination against viral diseases.

Although we found grade-related growth of inhibition on the GNG test, scores were not significantly associated with SES or academic achievement. Best et al. (2011) argued that more complex tests of EF are more predictive of academic success, and the GNG measure of inhibition is less complex than the tests of attention and working memory used in the present study. Cheung et al. (2004) found that in young adults, inhibition as measured by a GNG test was not correlated with three other measures of inhibition or any other tests of EF, while two of the other tests of inhibition (the Competing Motor Program and Stop Signal Response Task) were correlated with each other and other tests of EF. Not surprisingly, then, past studies using different measures of inhibition have found varying degrees of association with academic achievement, and other studies using the GNG test also failed to find associations with academic achievement (Noble et al., 2007; Vandenbroucke \& Baeyens, 2017). While different tests of inhibition may relate to the same general construct, the nature and degree of cognitive demand for successful inhibition seems to be related to the context of other cognitive operations in which it is required, leading to different degrees of association between inhibition and other measures depending on the specific measure of inhibition.

\section{Limitations}

This study had the advantage of a large and heterogenous sample of children, but it was a convenience sample comprised of schools using the C8 Sciences program. At the individual level of 5717 children we are confident the sample is truly representative. At the school level, the sample was more limited; but the 40 schools were distributed in urban and rural areas across the United States representing a full SES range. While validity criteria were applied to tests, some valid data may have been excluded or some invalid data included. Motivation for performance was not directly observed, and it is a potential confound even in individual administration under optimal conditions. However, using embedded validity checks is consistent with other on-line testing systems which have been well-accepted by the professional community. In addition, there are other dimensions of EF that we did not test and which if included might increase the degree of mediation by EF. Finally, there are limitations inherent in the correla- 
tional foundation of all mediation analyses such that EF compromise could be a correlate of some other variable that is the real causal mediator of the effects of poverty on academic outcomes. Since we aggregated data at the school level, this other variable could be some characteristic of the schools. However, the mediation analysis tested specific a priori assumptions based on extensive existing research showing that EF is related to both poverty and academic outcomes. Moreover, interventions to increase EF have been shown in randomized controlled studies to increases academic outcomes in children raised in poverty. These prior findings greatly increase the likelihood that EF is itself the mediator rather than being a "stand-in" variable for some other factor not similarly recognized or targeted in past research.

\section{Conclusion}

One set of previous research studies has established that executive functions predict academic, health and employment outcomes. Another set of studies has demonstrated that poverty compromises academic, health and employment outcomes. A third set of studies has shown that poverty compromises executive cognitive functions. This study provides more direct empirical support for the first time in a large and economically diverse population that poverty compromises academic outcomes by compromising executive function.

\section{Declaration of Interests}

Two of the authors, Professors Morris Bell and Bruce Wexler, have financial interest in the Yale start-up company C8 Sciences. A third author, Dr. Ahmet Esat Imal, is a part time employee of C8 Sciences. C8 Sciences have developed the assessments described in the paper, and an education intervention directed at improving cognitive skills and learning outcomes in children from poverty. The results presented in our manuscript support the value of the assessments done by $\mathrm{C} 8$ Sciences and the rationale for the $\mathrm{C} 8$ Sciences intervention. Because of this, Drs. Bell, Imal and Wexler could benefit financially from the publication of these findings. Pittman has no competing financial interest.

\section{Conflicts of Interest}

The authors declare no conflicts of interest regarding the publication of this paper.

\section{References}

Baron, R. M., \& Kenny, D. A. (1986). The Moderator-Mediator Variable Distinction in Social Psychological Research: Conceptual, Strategic, and Statistical Considerations. Journal of Personality and Social Psychology, 51, 1173-1182. https://doi.org/10.1037/0022-3514.51.6.1173

Best, J. R., Miller, P. H., \& Naglieri, J. A. (2011). Relations between Executive Function and Academic Achievement from Ages 5 to 17 in a Large, Representative National Sample. Learning and Individual Differences, 21, 327-336. 
https://doi.org/10.1016/j.lindif.2011.01.007

Blair, C., \& Raver, C. C. (2014). Closing the Achievement Gap through Modification of Neurocognitive and Neuroendocrine Function: Results from a Cluster Randomized Controlled Trial of an Innovative Approach to the Education of Children in Kindergarten. PLoS ONE, 9, e112393. https://doi.org/10.1371/journal.pone.0112393

Blair, C., \& Raver, C. C. (2016). Poverty, Stress, and Brain Development: New Directions for Prevention and Intervention. Academic Pediatrics, 16, S30-S36.

https://doi.org/10.1016/j.acap.2016.01.010

Blair, C., Raver, C. C., Granger, D., Mills-Koonce, R., \& Hibel, L. (2011). Allostasis and Allostatic Load in the Context of Poverty in Early Childhood. Development and Psychopathology, 23, 845-857. https://doi.org/10.1017/S0954579411000344

Cantin, R. H., Gnaedinger, E. K., Gallaway, K. C., Hesson-McInnis, M. S., \& Hund, A. M. (2016). Executive Functioning Predicts Reading, Mathematics, and Theory of Mind During the Elementary Years. Journal of Experimental Child Psychology, 146, 66-78. https://doi.org/10.1016/j.jecp.2016.01.014

Cheung, A. M., Mitsis, E. M., \& Halperin, J. M. (2004). The Relationship of Behavioral Inhibition to Executive Functions in Young Adults. Journal of Clinical and Experimental Neuropsychology, 26, 393-404. https://doi.org/10.1080/13803390490510103

Diamond, A., \& Ling, D. S. (2016). Conclusions about Interventions, Programs, and Approaches for Improving Executive Functions That Appear Justified and Those That, Despite Much Hype, Do Not. Developmental Cognitive Neuroscience, 18, 34-48. https://doi.org/10.1016/j.dcn.2015.11.005

Dilworth-Bart, J. E., Miller, K. E., \& Hane, A. (2012). Maternal Play Behaviors, Child Negativity, and Preterm or Low Birth-Weight Toddlers' Visual-Spatial Outcomes: Testing a Differential Susceptibility Hypothesis. Infant Behavior and Development, 35, 312-322. https://doi.org/10.1016/j.infbeh.2011.11.001

Haft, S. L., \& Hoeft, F. (2017). Poverty's Impact on Children's Executive Functions: Global Considerations. New Directions for Child and Adolescent Development, 158, 69-79. https://doi.org/10.1002/cad.20220

Hair, N. L., Hanson, J. L., Wolfe, B. L., \& Pollak, S. D. (2015). Association of Child Poverty, Brain Development, and Academic Achievement. JAMA Pediatrics, 169, 822-829. https://doi.org/10.1001/jamapediatrics.2015.1475

Hammond, S. I., Muller, U., Carpendale, J. I., Bibok, M. B., \& Liebermann-Finestone, D. P. (2012). The Effects of Parental Scaffolding on Preschoolers' Executive Function. Developmental Psychology, 48, 271-281. https://doi.org/10.1037/a0025519

Heissel, J. A., Sharkey, P. T., Torrats-Espinosa, G., Grant, K., \& Adam, E. K. (2018). Violence and Vigilance: The Acute Effects of Community Violent Crime on Sleep and Cortisol. Child Development, 89, e323. https://doi.org/10.1111/cdev.12889

Jensen, S. K. G., Berens, A. E., \& Nelson, C. A. (2017). Effects of Poverty on Interacting Biological Systems Underlying Child Development. The Lancet Child \& Adolescent Health, 1, 225-239. https://doi.org/10.1016/S2352-4642(17)30024-X

Kavanaugh, B. C., Tuncer, O. F., \& Wexler, B. E. (2018). Measuring and Improving Executive Functioning in the Classroom. Journal of Cognitive Enhancement, 1-10.

LCAH (2019). Tackling the Multidimensionality of Child Poverty. The Lancet Child \& Adolescent Health, 3, 199. https://doi.org/10.1016/S2352-4642(19)30067-7

Luby, J. L. (2015). Poverty's Most Insidious Damage: The Developing Brain. JAMA Pediatrics, 169, 810-811. https://doi.org/10.1001/jamapediatrics.2015.1682

Luby, J., Belden, A., Botteron, K., Marrus, N., Harms, M. P., Babb, C. et al. (2013). The 
Effects of Poverty on Childhood Brain Development: The Mediating Effect of Caregiving and Stressful Life Events. JAMA Pediatrics, 12, 1135-1142. https://doi.org/10.1001/jamapediatrics.2013.3139

Moffitt, T. E., Arseneault, L., Belsky, D., Dickson, N., Hancox, R. J., Harrington, H. et al. (2011). A Gradient of Childhood Self-Control Predicts Health, Wealth, and Public Safety. Proceedings of the National Academy of Sciences of the United States of America, 108, 2693-2698. https://doi.org/10.1073/pnas.1010076108

Nelson, T. D., Nelson, J. M., James, T. D., Clark, C. A. C., Kidwell, K. M., \& Espy, K. A. (2017). Executive Control Goes to School: Implications of Preschool Executive Performance for Observed Elementary Classroom Learning Engagement. Developmental Psychology, 53, 836-844. https://doi.org/10.1037/dev0000296

Neville, H. J., Stevens, C., Pakulak, E., Bell, T. A., Fanning, J., Klein, S., \& Isbell, E. (2013). Family-Based Training Program Improves Brain Function, Cognition, and Behavior in Lower Socioeconomic Status Preschoolers. Proceedings of the National Academy of Sciences of the United States of America, 110, 12138-12143.

https://doi.org/10.1073/pnas.1304437110

Noble, K. G., Houston, S. M., Brito, N. H., Bartsch, H., Kan, E., Kuperman, J. M. et al. (2015). Family Income, Parental Education and Brain Structure in Children and Adolescents. Nature Neuroscience, 18, 773-778. https://doi.org/10.1038/nn.3983

Noble, K. G., McCandliss, B. D., \& Farah, M. J. (2007). Socioeconomic Gradients Predict Individual Differences in Neurocognitive Abilities. Developmental Science, 10, 464-480. https://doi.org/10.1111/j.1467-7687.2007.00600.x

Pingault, J. B., Tremblay, R. E., Vitaro, F., Carbonneau, R., Genolini, C., Falissard, B., \& Cote, S. M. (2011). Childhood Trajectories of Inattention and Hyperactivity and Prediction of Educational Attainment in Early Adulthood: A 16-Year Longitudinal Population-Based Study. American Journal of Psychiatry, 168, 1164-1170. https://doi.org/10.1176/appi.ajp.2011.10121732

Preacher, K. J., \& Hayes, A. F. (2004). SPSS and SAS Procedures for Estimating Indirect Effects in Simple Mediation Models. Behavior Research Methods, Instruments, \& Computers, 36, 717-731. https://doi.org/10.3758/BF03206553

Ready, D. D., \& Reid, J. L. (2019). Children's Executive Function Development and School Socio-Economic and Racial/Ethnic Composition. Early Childhood Research Quarterly, 47, 457-471. https://doi.org/10.1016/j.ecresq.2018.08.002

Sharkey, P. T., Tirado-Strayer, N., Papachristos, A. V., \& Raver, C. C. (2012). The Effect of Local Violence on Children's Attention and Impulse Control. American Journal of Public Health, 102, 2287-2293. https://doi.org/10.2105/AJPH.2012.300789

Tomalski, P., Moore, D. G., Ribeiro, H., Axelsson, E. L., Murphy, E., Karmiloff-Smith, A. et al. (2013). Socioeconomic Status and Functional Brain Development-Associations in Early Infancy. Developmental Science, 16, 676-687.

https://doi.org/10.1111/desc.12079

Vandenbroucke, L., \& Baeyens, D. (2017). The Development of Executive Functioning across the Transition to First Grade and Its Predictive Value for Academic Achievement. Learning and Instruction, 49, 103-112.

https://doi.org/10.1016/j.learninstruc.2016.12.008

Waber, D. P., Gerber, E. B., Turcios, V. Y., Wagner, E. R., \& Forbes, P. W. (2006). Executive Functions and Performance on High-Stakes Testing in Children from Urban Schools. Developmental Neuropsychology, 29, 459-477. https://doi.org/10.1207/s15326942dn2903 5

Walker, S. P., Chang, S. M., Powell, C. A., \& Grantham-McGregor, S. M. (2005). Effects 
of Early Childhood Psychosocial Stimulation and Nutritional Supplementation on Cognition and Education in Growth-Stunted Jamaican Children: Prospective Cohort Study. The Lancet, 366, 1804-1807. https://doi.org/10.1016/S0140-6736(05)67574-5

Welsh, J. A., Nix, R. L., Blair, C., Bierman, K. L., \& Nelson, K. E. (2010). The Development of Cognitive Skills and Gains in Academic School Readiness for Children from Low-Income Families. Journal of Educational Psychology, 102, 43-53.

https://doi.org/10.1037/a0016738

Wexler, B. E., Iseli, M., Leon, S., Zaggle, W., Rush, C., Goodman, A. et al. (2016). Cognitive Priming and Cognitive Training: Immediate and Far Transfer to Academic Skills in Children. Scientific Reports, 6, Article No. 32859. https://doi.org/10.1038/srep32859

Yeniad, N., Malda, M., Mesman, J., van Ijzendoorn, M. H., \& Pieper, S. (2013). Shifting Ability Predicts Math and Reading Performance in Children: A Meta-Analytical Study. Learning and Individual Differences, 23, 1-9.

https://doi.org/10.1016/j.lindif.2012.10.004 